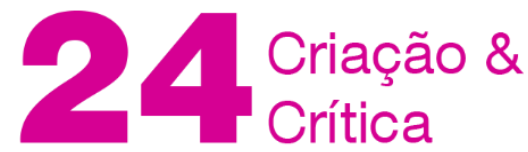

\author{
INUNDAÇÃO ${ }^{1}$
}

Autor:

Kobo $\mathrm{Abe}^{2}$

Tradução e notas:

Renan Kenji Sales Hayashi ${ }^{3}$

\begin{abstract}
Resumo: Este trabalho apresenta uma tradução do conto The Flood (Kouzui), escrito pelo autor japonês Kobo Abe. Feita em 1950, a obra expressa uma proposta de fim da humanidade a partir da liquefação da população. O texto, ainda inédito em português do Brasil, traz a manifestação literária de Abe em uma visão que opera entre a lógica do absurdo, a ficção científica e o pós-apocalipse, salientando criticamente a forma do homem de se relacionar com o trabalho, o espaço urbano e o poder econômico.
\end{abstract}

PaLAVRAS-CHAVE: Tradução literária; Kobo Abe; Literatura Japonesa; Apocalipse.

ABSTRACT: This article presents a translation of Kobo Abe's short story The Flood (Kouzui). Written by the Japanese author in 1950, the narrative conveys an idea of the end of humanity from the liquefaction of the population. The text, still unpublished in Brazilian Portuguese, reveals Abe's literary manifestation through a vision operating with the logic of absurdity, science fiction and the post-apocalypse, critically emphasizing the way men relate to work, urban space and economic power.

KEYwORDS: Literary translation; Kobo Abe; Japanese literature; Apocalypse.

1 Originalmente publicado em japonês (1950), sob o título 洪水 (kouzui).

2 Kobo Abe é o nome literário de Kimifusa Abe (1924-1993), escritor japonês reconhecido por suas obras ficcionais embebidas de episódios surrealistas, da ordem do absurdo e de um tom futurista singular.

3 Docente na ESAMC/Campinas. Doutorando em Linguística Aplicada (Unicamp). Mestre em Linguística Aplicada (UnB). kenji.hayashi.backup@gmail.com 


\section{$24^{\text {cratacáo }}$}

\section{Traduzir Kobo Abe - Apresentação}

Nunca se escreve nem na própria língua, nem numa língua estrangeira

(DERRIDA, 1986, p. 146)

Traduzir Kobo Abe: um desafio. Em primeiro lugar, pelo estranhamento gerado ao chamá-lo, nos padrões ocidentais, com seu sobrenome após o nome: Kobo Abe. Entre apreciadores e estudiosos deste autor, nascido em 1924, em Tóquio, costumamos incitá-lo a partir do padrão japonês de sobrenome em primeiro lugar. Assim, o nosso Abe Kobo está de volta. Contudo, a despeito desse preciosismo, trazer esse nome à baila - que, ressalto, não era nome, mas um pseudônimo literário de Kimifusa Abe - implica em evocar uma série de associações e efeitos causados pela diversidade de sua produção literária.

De início, podemos ressaltar o volume expressivo de produções desse autor. Muito hábil nas peças de teatro e nos contos, seu nome ganhou destaque com as produções de histórias mais longas (nem sempre romances), frequentemente com um tom de surrealismo, futurismo e pós-modernidade que, por vezes, beiram o absurdo. Aliás, afirmar que uma parte da obra de Abe está fincada nas terras do absurdo não é, nem de longe, um erro ou uma crítica com intuito de desqualificá-la. Ao contrário, é exatamente por conta do absurdo que muito do que ele escreveu opera entre a genialidade e o ineditismo, especialmente tendo como pano de fundo a cultura japonesa do século XX.

Como exemplo, podemos citar peças teatrais nas quais os mortos, além de se comunicarem, são debochados e ácidos ${ }^{4}$, quase imbuídos do papel que os loucos tinham na antiguidade, como aqueles que são responsáveis por dizer a verdade, a dura e cruel verdade. Além disso, há dezenas de obras que tratam do corpo humano, não em seu aspecto existencialista; mas pela matéria, a partir do viés orgânico que dá sustentação à crítica e à reflexão profunda sobre a humanidade, como é o caso do texto - 洪水 (kouzui)/ The Flood (1950) - ora traduzido.

Não por acaso Abe trabalha essas temáticas, em especial a referente à matéria orgânica. Médico de formação e filho de pai igualmente médico, Abe nunca exerceu a profissão. Não diretamente, pois seu conhecimento do corpo humano esteve refletido em grande parte de sua obra; contudo, não de maneira a endossar descrições fiéis, detidas e comportadas. Tais descrições estiveram a serviço de um jogo que buscava no orgânico a chave para compreender o inorgânico.

$E$, seguindo essa proposta, buscava no absurdo uma ótica para enxergar a sensatez. Trabalhando com o absurdo, não demorou para ser comparado a outros autores da literatura mundial com obras de temática aproximada, como o tcheco Franz Kafka (1883-

\footnotetext{
4 Peça teatral de Kobo Abe, おまえにも罪がある (Omae nimo tsumi ga aru), de 1965, ainda sem tradução para o português do Brasil.
} 


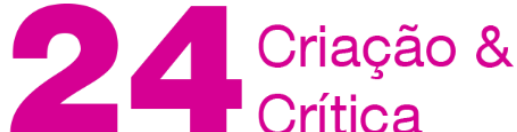

1924). Angelika Zahn (2009) ${ }^{5}$, via literatura comparada, sustenta a tese de que Kobo Abe poderia ser o Kafka japonês. Ela empreende essa análise a partir de uma das obras mais conhecidas de Abe, The face of another (1964), uma das poucas que recebeu tradução para o português do Brasil, com o título de O rosto de um outro (2015).

Entretanto, resta-nos a pergunta: podemos defender que Abe seja um Kafka japonês? Penso que uma maneira interessante seria compreender a obra de Abe por ela mesma, dada sua complexidade e especificidade. Muito embora comparações sejam, de fato, importantes, é difícil estabelecer paralelos equânimes com o que se vê em Abe sem incorrer em injustiças, não só com a obra do autor japonês, como também o escritor comparado.

Dessa forma, com a presente tradução, desejamos viabilizar uma leitura de um exemplo da obra de Abe, ainda pouco traduzida no Brasil. Pensamos que se trata de uma oportunidade de trazer para o ambiente digital um excerto desse vulto de produções que articulam o absurdo e a crítica social, o corpo humano e a podridão do lixo, a vida plena e a existência por um fio. Por tudo isso, acreditamos que a presente tradução seja relevante. Contudo, não queremos dizer com isso que o texto tenha sido fácil de traduzir. A escrita de Abe, por seu conhecimento médico, é bem específica em certos momentos, o que torna dolorosa e deliciosa a tarefa do tradutor, que fica em eterna dívida com o texto-fonte.

No caso do conto ora traduzido, essa dívida começa pelo título. Em japonês, Abe nomeou o conto, como kouzui (洪水), o que poderia significar "inundação", "dilúvio", "enchente". À primeira vista, todas essas palavras poderiam dar título ao conto traduzido, porque compõem um mesmo campo semântico. Contudo, a opção por uma ou por outra possibilitaria diferentes efeitos de sentido que poderiam ou não ter sido contemplados pelos fios do texto. Por exemplo, optando por "dilúvio", imediatamente temos em mente a mitologia bíblica que narra a terra coberta por água, diante do arrependimento de Jeová em ter criado o homem, restando apenas Noé - homem centenário - sua arca e os animais. De fato, no conto de Abe, Noé aparece, já ao final, para compor um quadro pós-apocalíptico depois dos homens todos terem se liquefeito. Aqui, a água do dilúvio é composta de humanos. Em contraponto, o que se pode argumentar é que a palavra "dilúvio" pressupõe chuvas intensas que inundam todas as superfícies terrestres, não restando outra possibilidade senão desbravar o mar.

No texto, ocorrem precipitações, mas a causa principal da inundação não é a chuva, mas a liquefação de corpos humanos. O que nos coloca diante de um problema conceitual geológico: é correto nomear como dilúvio, seguindo uma mitologia bíblica, se a causa da enchente do conto não é a chuva?

Recorrendo ao texto em inglês, mantemos a impossibilidade de uma escolha imediata. O título dado foi "The Flood", o que também pode significar "dilúvio", "inundação" ou "enchente". Muito embora seja digno de nota que nas versões em língua inglesa da bíblia, a escolha lexical mais frequente tenha sido deluge, não flood.

5 ZAHN, Angelika. Kobo Abe - der japanische kafka? ein vergleich zwischen abes "Das Gesicht des Anderen". Berlim: Editora Grin Verlag, 2009. 


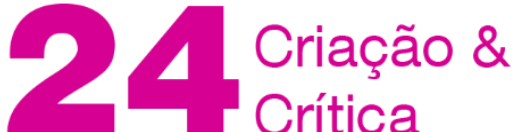

Diante do impasse, dessa indecidibilidade derridiana, empreendemos a decisão; o corte no texto. Elegemos "inundação". Optamos por esta palavra para nos atermos às definições geológicas/geográficas do termo - sem as quais não poderíamos ter decidido. Segundo o Centro de Estudos Geográficos e Ordenamento do Território, inundações são fenômenos hidrológicos extremos, de frequência variável, que podem ser naturais ou de ação humana, que consistem na submersão de uma área que é usualmente emersa. Diante do que Abe nos apresenta, pensamos que, de posse desse conhecimento, a escolha por 'inundação' fique mais coerente para ser o título da obra que se segue nas linhas abaixo.

Embora abertas à crítica e discussão, as opções do tradutor foram feitas com esse olhar, tentando trazer para o texto traduzido palavras cujos efeitos de sentido pudessem apresentar ao leitor um quadro panorâmico daquilo mesmo que Abe trouxe nas linhas do conto: o fim da humanidade. Tarefa difícil. Tarefa (quase) impossível. Tarefa indecidível. E na indecisão mesmo que operamos. Entre erros e acertos, vamos cortando os fios do texto em uma língua e recompondo o tecido em outra, ora acertando, ora errando, não por descuido, mas por inundações de sentido, dilúvio de ideias e enchente de emoções. 


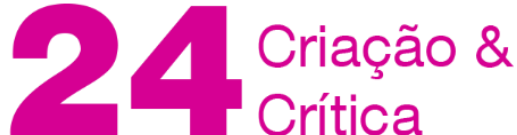

\section{Inundação}

Kobo Abe

\section{A humanidade está ameaçada por uma nova enfermidade: liquefação.}

Um tipo pobre - porém honesto - de filósofo, estudando as leis do universo, levou um telescópio até o topo de seu cortiço e buscou os movimentos de corpos celestes. Como de costume, ele parecia incapaz de descobrir mais do que um tanto de estrelas cadentes sem importância e outras tantas em suas posições usuais. Não que ele estivesse entediado, ou coisa do tipo, mas ocorreu a ele de virar casualmente seu telescópio em direção à Terra. Uma estrada invertida se apareceu diante de seu nariz. Um trabalhador, igualmente invertido, apareceu caminhando para trás ao longo da via invertida. Ordenando essas imagens em sua cabeça e, devolvendo-as para suas relações habituais, 0 filósofo ajustou as lentes e seguiu os movimentos do trabalhador. Sob as lentes de largo diâmetro, o interior da pequena cabeça do trabalhador era transparente. O motivo era porque o trabalhador, de volta para casa após um turno noturno na fábrica, não tinha nada em sua cabeça que não fosse exaustão.

Contudo, o persistente filósofo, sem desviar por esse motivo as lentes para o lado, continuou seguindo o caminho do trabalhador. A paciência do filósofo seria, em breve, recompensada. Repentinamente, várias alterações aconteceram com trabalhador.

A silhueta do corpo do dele, inesperadamente, tornou-se esmaecida. Derretendo-se a partir dos pés, a figura ajoelhou-se pegajosamente e se dissolveu. Apenas as roupas, o boné e os sapatos permaneceram junto à massa de líquido encarnado. Por fim, completamente fluído, se espalhou uniformemente no chão.

O trabalhador liquefeito silenciosamente começou a escorrer em direção ao pavimento subterrâneo. Ele escorreu através de um buraco no asfalto. Em seguida, ele rastejou para fora. Este movimento do trabalhador liquefeito, desafiando as leis da hidrodinâmica, impressionou tanto o filósofo, que ele quase deixou o telescópio cair. Escorrendo para frente, o trabalhador - quando se viu diante de uma cerca da estrada - rastejou para cima como se fosse uma lesma deslizando em sua membrana e desapareceu de vista por cima da cerca. $O$ filósofo, tirando seu olho do telescópio, soltou um suspiro profundo. No dia seguinte, ele anunciou ao mundo a vinda de uma grande inundação.

Na verdade, a liquefação de trabalhadores e de pessoas pobres já havia começado em todos os lugares do mundo. As liquefações em grupo eram particularmente impressionantes. Em uma fábrica grande, o maquinário parava subitamente. Os trabalhadores, deliquescendo todos de uma vez só, formavam 


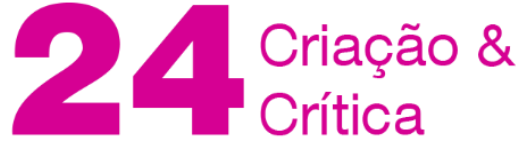

uma massa de líquido que escorria em um fluxo por debaixo da porta ou rastejava parede acima, fluindo para fora da janela. Às vezes, o processo era reverso: depois de os trabalhadores terem se tornado líquido, apenas o maquinário na fábrica deserta, continuava funcionando desatinadamente até que, por fim, enguiçavam. Além disso, fugas das prisões, por conta da liquefação em massa dos prisioneiros e pequenas inundações causadas pela liquefação de populações inteiras de povoados agrícolas foram reportadas sucessivamente nos jornais.

A liquefação dos seres humanos, não limitado a este tipo de anomalia fenomenal, possibilitou uma confusão de formas variadas. Crimes perfeitos devido à liquefação dos criminosos aumentaram drasticamente. A lei e a ordem foram ameaçadas. A polícia, secretamente consultando físicos, começou uma investigação sobre as propriedades dessa água. Contudo, o líquido, completamente alheio às leis científicas dos fluídos, simplesmente mergulhava os físicos em uma confusão absurda. Muito embora ao toque não fosse nada diferente da água convencional, em algumas situações, apresentava uma tensão superficial firme, como o mercúrio, e podia preservar sua forma, como uma ameba. De tal forma, não só podia rastejar, como dito anteriormente, de um lugar mais baixo para um mais alto, mas também depois de se misturar perfeitamente com seus semelhantes humanos e outros tipos de líquidos naturais, em um impulso ou outro, poderiam também se separar em seu volume original. Além disso, de forma inversa, a água apresentava, por vezes, uma tensão superficial fraca como a do álcool. Nessas situações, tinha um poder extraordinário de infiltração em contato com todos os sólidos. Por exemplo, em certas situações, provavelmente em relação às diferenças de uso, com o mesmo tipo de papel, a água poderia tanto dissolvê-lo quimicamente, quanto não ter absolutamente nenhum efeito.

Os humanos liquefeitos também eram capazes de se congelar ou de evaporar. Os pontos de congelamento e de evaporação eram variáveis. Trenós deslizando sobre gelo espesso seriam engolidos, com cavalo e tudo, pelo gelo derretido repentinamente. Os atletas na linha de frente em competições de patinação desapareciam abruptamente. Além disso, piscinas congelavam repentinamente em pleno verão, mantendo em poses congeladas garotas que estiveram nadando. Os humanos liquefeitos rastejavam para o topo de montanhas, se misturavam aos rios, atravessavam oceanos, evaporavam-se em nuvens e caiam como chuva, para então se espalhar por todo o mundo. Ninguém poderia prever quando ou onde, nem que tipo de coisas estavam para acontecer. Experimentos químicos se tornaram quase impossíveis. Os geradores das máquinas a vapor, por conta da contaminação de pessoas líquidas, tornaram-se completamente inutilizáveis. Não importava o quanto alimentassem as máquinas, não havia subida de pressão. Ou, subitamente, as pessoas líquidas expandiam violentamente e explodiam os geradores. Peixes e plantas, que 
tiveram uma relação vital com a água, estavam em um estado de caos para além de qualquer descrição. Em todos os campos da biologia, transformações eram difíceis de calcular e destruições começaram. Maças rolavam trinando trechos de melodia; talos de arroz estouravam com ruídos semelhantes aos de rojões. Particularmente sérios eram os efeitos nos seres humanos que ainda não haviam deliquescidos, em especial, as pessoas ricas.

Certa manhã, o proprietário de uma grande fábrica morreu afogado em uma xícara de café, tão logo que colocou seus lábios na xícara. Outro industrialista morreu afogado em um copo de whiskey. Um caso extremo foi um afogamento em uma única gota de colírio. Isto parece coisa muito difícil de acreditar, mas tudo isso aconteceu.

Conforme esses fatos foram noticiados, muitas pessoas ricas contraíram hidrofobia, na verdadeira acepção da palavra. Um certo alto funcionário do governo fez a seguinte confissão: "quando eu estou prestes a beber, eu olho a água no copo e já não parece mais água para mim. Em suma, é um mineral liquidificado, uma substância nociva que é impossível de digerir. Se eu tomar uma golada, estou certo de que ficaria doente imediatamente. Eu seria invadido por trágicos medos instantaneamente".

Mesmo quando não era o caso de disfagia, claramente se tratava de hidrofobia. Em todos os lugares, havia casos de velhas que desmaiavam ante a simples visão de água. No entanto, vacinas antirrábicas não serviam para nada.

Por ora, de um fim do mundo ao outro, vozes invisíveis se misturavam em um coro lamentando a ruína pela grande inundação. Contudo, os jornais, categoricamente negando esses rumores, publicaram as seguintes explicações:

a) As chuvas deste ano, tanto as regionais quanto as globais, estão abaixo da média anual;

b) Todos os rios que foram notificados por terem inundado não excederam a variação sazonal para um ano comum;

c) Nenhuma anormalidade meteorológica ou geológica foi observada.

Estes eram os fatos. Mas também era fato que a inundação já havia começado. Esta contradição causou uma perturbação social geral. Já estava claro para todos que esta não era uma inundação comum. Naquele momento, mesmo os jornais foram forçados a admitir a realidade da inundação. Mas no tom otimista usual deles, eles reiteraram que isso ocorreu por conta de algum acidente cósmico. Não era nada além de temporário e chegaria ao fim por conta própria. Contudo, a inundação, se espalhando diariamente, engoliu muitos povoados e muitas cidades e planícies; pequenos morros foram submersos pelas pessoas líquidas e as pessoas de status, as pessoas abastadas, começaram uma debandada competitiva para se refugiar nas zonas de montanhas e distritos montanhosos. Embora tenham percebido que aquele tipo de ação era inútil contra as pessoas líquidas, que escalavam até mesmo paredes, eles eram incapazes de pensar em qualquer coisa diferente para fazer. 


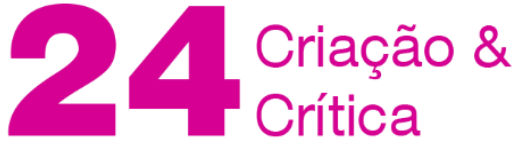

Finalmente, até mesmo os presidentes e primeiros-ministros admitiram a urgência da situação. Proclamações foram proferidas, afirmando que para salvar a humanidade da extinção nessa inundação, era necessário todos os recursos espirituais e materiais, acelerando a construção de grandes barragens e represas. Para este propósito, dezenas de milhares de trabalhadores foram retidos para trabalho compulsório. Nesse caso, os jornais também, subitamente mudando de postura, concordaram com as proclamações e enalteceram a alta moralidade dos políticos e seu senso de dever público. Contudo, praticamente toda a gente, incluindo presidentes e primeiros-ministros, sabia que aquelas proclamações não eram nada além de proclamações esvaziadas de sentido. Barragens e represas contra as pessoas líquidas seriam nada mais do que dinâmicas de Newton contra dinâmicas quânticas, sendo completamente ineficazes. Não apenas isso, mas os trabalhadores que estavam construindo as barragens se transformaram rapidamente em líquido bem ao lado das barragens. As páginas de "itens pessoais" dos jornais estavam inundadas com avisos de pessoas desaparecidas. Entretanto, a bem da verdade, os jornais lidaram com muitos dos desaparecimentos simplesmente como efeito, ao invés de causa da inundação. Diante da natureza contraditória da inundação e de sua causa essencial, eles mantiveram um silêncio resoluto, recusando-se até mesmo a mencionar o assunto.

Nesse momento, havia um cientista que propôs que líquido que cobriu a Terra poderia ser volatilizado por meio da energia nuclear. Os governos, indicando rapidamente anuência, ofereceram assistência completa. Contudo, quando eles tentaram começar, o que ficou claro, a despeito das várias dificuldades, era a impossibilidade do projeto. Por conta da liquefação dos seres humanos, a qual estava crescendo em progressão geométrica, não havia trabalhadores suficientes para substituição adequada. Além disso, a liquefação já estava ocorrendo também entre os cientistas. Ademais, as fábricas de peças estavam sendo progressivamente destruídas e engolidas pelas águas. Atormentados por problemas de reorganização e reconstrução, os governos não podiam prever quando a produção de equipamento nuclear vital começaria.

Tumulto e agitação varreram o mundo. Pessoas estavam virando múmias por conta da desidratação, emitindo ruídos fortes e ofegantes toda vez que respiravam.

Havia apenas uma pessoa que estava calma e feliz. Era o otimista e astuto Noé. Noé, com sua experiência com a inundação anterior, sem ficar nervoso ou em pânico, trabalhava cuidadosamente em sua arca. Quando ele pensava que o futuro da raça humana fora confiado somente a ele e sua família, ele era, até mesmo, capaz de mergulhar em uma exaltação religiosa.

Neste momento, quando a inundação se aproximava de sua casa, Noé, acompanhado de sua família e de animais domésticos, embarcaram na arca. 


\section{$244_{\text {caracác \& }}^{\text {Can }}$}

Imediatamente, as pessoas líquidas começaram a rastejar para cima, nos dois lados do barco. Noé os repreendeu em alta voz.

"Ei! Vocês acham que esse barco é de quem? Eu sou Noé. Esta é a arca de Noé. Não se enganem. Andem, deem o fora daqui!".

Entretanto, pensar que o líquido, o qual não era mais humano, poderia compreender suas palavras era claramente uma conclusão precipitada e um erro de cálculo. Para o líquido, só há problemas de líquido. No minuto seguinte, a arca estava repleta de líquido e das criaturas viventes afogadas. A arca abandonada boiou à deriva ao sabor do vento.

Dessa forma, a humanidade pereceu diante da Segunda Inundação. Mas, se alguém pudesse ter olhado as esquinas das ruas e de debaixo das árvores dos povoados no fundo das águas, agora pacíficas, poderia ter visto uma substância cintilante começando a cristalizar. Provavelmente, ao redor do núcleo invisível das pessoas líquidas supersaturadas.

\section{Referências}

ABE, K. The Flood (1950). In: APOSTOLOU, John; GREENBERG, Martin (Orgs). The best Japanese Science fiction stories. Nova lorque: Barricade Books Inc, 1997, p. 21-27.

DERRIDA, J. Survivre. Journal de bord. In: DERRIDA, Jacques. Parages. Paris: Galilée, 1986.

ZAHN, A. Kobo Abe: der japanische kafka? Ein vergleich zwischen abes "Das Gesicht des Anderen". Berlim: Editora Grin Verlag, 2009.

Recebido em: 30/04/2019 Aceito em: 26/05/2019

Referência eletrônica: HAYASHI, Renan Kenji Sales. Inundação. Criação \& Crítica, n. 24, p., out. $2019 . \quad$ Disponível em: <http://revistas.usp.br/criacaoecritica>. Acesso em: dd mmm. aaaa. 